\title{
Micro-Raman Investigation of Hydrogen Localized in Cone-Shaped Defects Formed on the Silicon Wafer Surface
}

\author{
N.V. Frantskevich ${ }^{a}$, A.K. Fedotov ${ }^{b}$, A.V. Frantskevich ${ }^{a, *}$ And N.V. Mazanik $^{c}$ \\ ${ }^{a}$ Belarusian National Technical University, Minsk, 220063, Belarus \\ ${ }^{b}$ Belarusian State University, Minsk, 220030, Belarus \\ ${ }^{c}$ Belarusian State Technological University, Minsk, 220006, Belarus
}

\begin{abstract}
The goal of this work is the micro-Raman study of molecular hydrogen localized in cone-shaped defects, which are formed on the surface of previously helium implanted and annealed Czochralski Si wafers as a result of hydrogen plasma treatment. The line at $\approx 4158 \mathrm{~cm}^{-1}$ corresponding to molecular hydrogen is observed in the Raman spectra when the laser beam is focused both on cone-shaped defects or defect-free regions of the surface. The laser irradiation of cone-shaped defects during micro-Raman experiments leads to intensity increase of this line when the irradiation time is increasing, with subsequent appearance of lines at $\approx 3621$ and $\approx 3698 \mathrm{~cm}^{-1}$ and simultaneous disappearance of $4158 \mathrm{~cm}^{-1}$ line. No such effect was observed when the laser beam was focused on defect-free regions. The experiments have shown that heat treatment of the samples studied causes the appearance in the Raman spectra of lines at $\approx 3468, \approx 3621$, and $\approx 3812 \mathrm{~cm}^{-1}$, which can be associated with molecular hydrogen.
\end{abstract}

DOI: $10.12693 /$ APhysPolA.125.1332

PACS: 78.30.Am, 61.72.uf

\section{Introduction}

In Ref. [1] the possibility to form an array of cone-shaped defects on the silicon wafer surface after the hydrogen plasma treatment was demonstrated. However, the nature and formation mechanism for these defects are still ambiguous. On the other hand, the Raman spectroscopy allows to detect local vibrational modes corresponding to molecular hydrogen localized in different positions of silicon lattice: (i) tetrahedral interstitial [2-4], (ii) multivacancies $[5-7]$, (iii) platelets $[8,9]$, (iv) blisters [10]. Thus, the micro-Raman analysis of molecular hydrogen localized in (nearby) cone-shaped defects can provide an information about their nature and properties.

\section{Experimental}

Standard $p$-type $10 \Omega \mathrm{cm}$ Czochralski $(\mathrm{Cz})$ grown $\mathrm{Si}$ wafers were implanted by helium ions with energy of $300 \mathrm{keV}$ and fluence of $5 \times 10^{15}$ at $/ \mathrm{cm}^{2}$. The calculated projected range of the implanted ions at room temperature was equal to $2 \mu \mathrm{m}$. After the introduction of helium by implantation the samples were annealed in vacuum at $600{ }^{\circ} \mathrm{C}$ during $1 \mathrm{~h}$. After them, hydrogen was introduced into silicon from a DC plasma at $100^{\circ} \mathrm{C}$. The energy of ions during the plasma treatment was $2 \mathrm{keV}$ and the treatment period was 30 min with the current density of $3 \mu \mathrm{A} / \mathrm{cm}^{2}$.

\footnotetext{
* corresponding author; e-mail: a.frantskevich@rambler.ru
}

The Raman spectra were obtained at room temperature in a Raman microspectrometer using an $\mathrm{Ar}^{+}$laser of wavelength $488 \mathrm{~nm}$ at a power of $20 \mathrm{~mW}$. The laser beam was focused at the sample using a microscope $(100 \times$ lens). The backscattered Raman signal without polarization was analyzed by a $0.3 \mathrm{~m}$ focal length spectrograph (grating $1800 \mathrm{~mm}^{-1}$ ) and detected by a cooled Si-CCD detector array. SEM study of the samples studied was done using LEO 1455 microscope.

\section{Results and discussion}

In Fig. 1 SEM image of cone-shaped defects formed on the $\mathrm{Cz}$ Si wafer surface, as well as the Raman spectra taken on defect-free region (curve h1) and cone-shaped defects (curves h2, h3) are presented.

The experiments have shown that the spectral shape of the silicon one phonon line $\left(520 \mathrm{~cm}^{-1}\right)$ is the same for the cone-shaped defects, defect-free regions, as well as for the reference Si wafer. At the same time, in the Raman spectra taken from some cone-shaped defects the lines at $\approx 3621$ and $\approx 3698 \mathrm{~cm}^{-1}$ can be detected (for a part of cone-shaped defects, these lines are not observed). The line at $\approx 3621 \mathrm{~cm}^{-1}$ corresponds to the molecular hydrogen localized in tetrahedral interstitials [2-4].

It is well known that in micro-Raman spectroscopy the focused laser light can cause a strong local heating of the studied sample that can lead to modification of its properties. In this connection, we performed additional experiments, where the influence of the local laser annealing on the Raman spectra was studied. We selected cone-shaped defect, which did not reveal the lines at $\approx 3621$ and $\approx 3698 \mathrm{~cm}^{-1}$ in the Raman spectrum. After that, this defect was subjected to the laser beam irradiation 


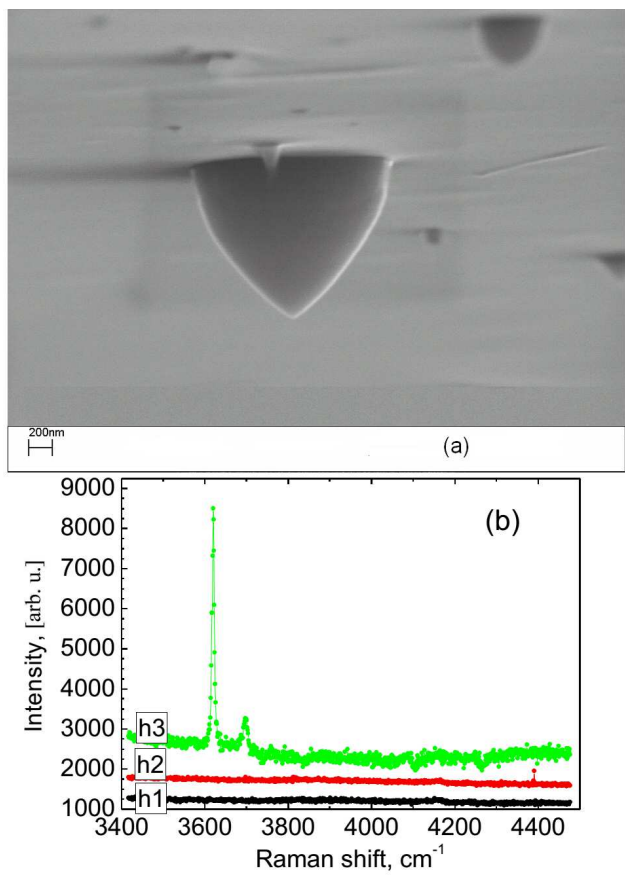

Fig. 1. SEM image (a) and Raman spectra (b) for $\mathrm{Cz} \mathrm{Si}$ wafer after helium implantation, annealing and hydrogen plasma treatment. Raman spectra were taken when the laser beam was focused on defect-free region (h1) and cone-shaped defects (h2, h3).

with a periodic measurement of the Raman spectra. The maximal irradiation time was equal to $28 \mathrm{~h}$. The Raman spectra for the irradiation times $0-5 \mathrm{~h}$ and $6-28 \mathrm{~h}$ are presented in Fig. 2a and b, respectively.

One can see that the laser irradiation of cone-shaped defects during micro-Raman experiments leads to the intensity increase of the line at $\approx 4144 \mathrm{~cm}^{-1}$ with irradiation time (curves T1-T3 in Fig. 2a). However, after a long-time laser irradiation the lines at $\approx 3621$ and $\approx 3698 \mathrm{~cm}^{-1}$ appear in the Raman spectra with simultaneous disappearance of the $4144 \mathrm{~cm}^{-1}$ line (curves $\mathrm{T} 4-\mathrm{T} 8)$.

To compare the influence of the local (laser) and uniform heating, the experiments described below were done. In these experiments the laser beam was focused on cone-shaped defect, which did not reveal the lines at $\approx 3621$ and $\approx 3698 \mathrm{~cm}^{-1}$ in the Raman spectrum. Then the sample was subsequently annealed at 150, 200, 250 , and $300{ }^{\circ} \mathrm{C}$ during $10,20,30$, and $40 \mathrm{~min}$, respectively (laser beam was switched off during this annealing). After each step of annealing, the Raman spectra were taken at room temperature. These spectra are presented in Fig. 3.

As is seen from Fig. 3, the increase of the temperature and time of annealing leads to increase of the intensity of the Raman line at $\approx 4133-4144 \mathrm{~cm}^{-1}$. The similar increase of the molecular hydrogen related lines in the Raman spectra was observed in [8]. One can see that the annealing leads to an appearance of lines at $\approx 3468$,
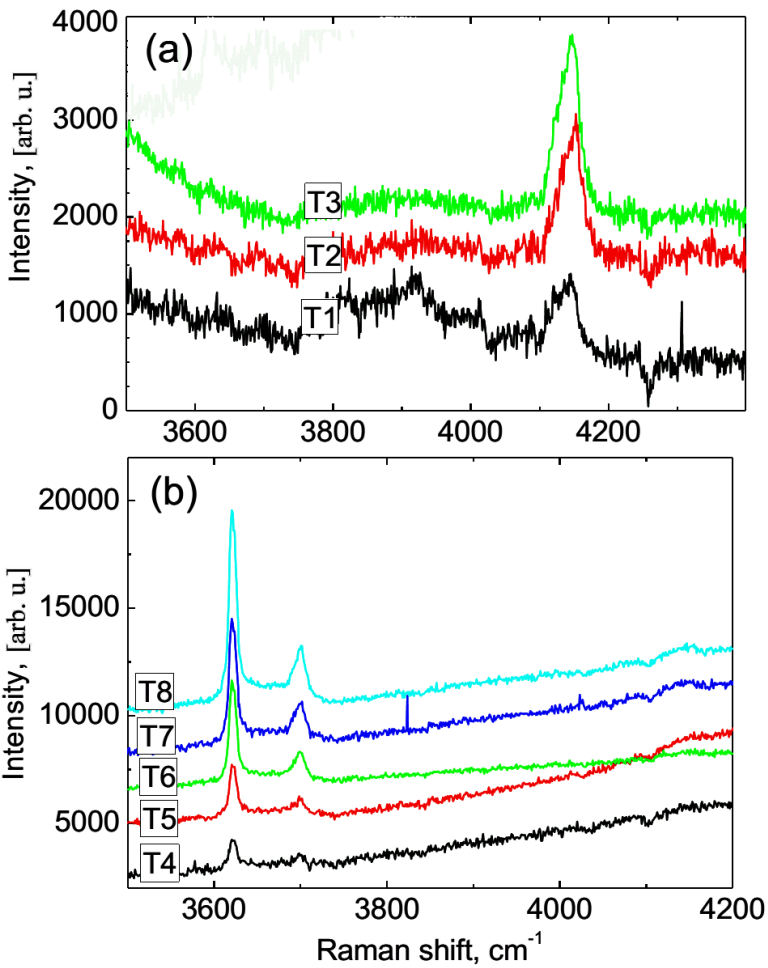

Fig. 2. Raman spectra taken on cone-shaped defects after laser beam irradiation during $0,4,5,6,8,18,24$, and $28 \mathrm{~h}$ (curves T1-T8, respectively).

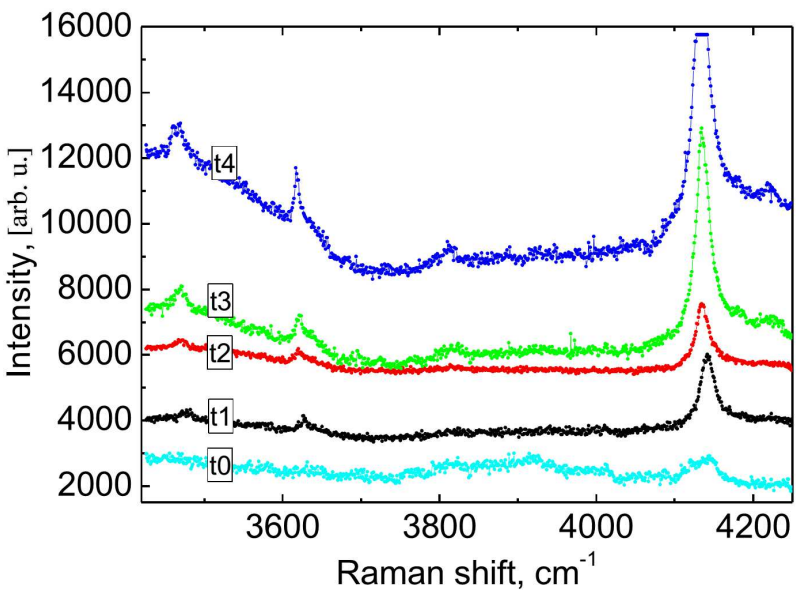

Fig. 3. Raman spectra taken on cone-shaped defects after annealing at 150 (t1), 200 (t2), 250 (t3) and $300{ }^{\circ} \mathrm{C}(\mathrm{t} 4)$. Spectrum t0 was taken before annealing.

$\approx 3621$, and $\approx 3812 \mathrm{~cm}^{-1}$. The last line corresponds to the molecular hydrogen in multivacancies [5-7].

According to our knowledge, the line at $\approx 3468 \mathrm{~cm}^{-1}$ was not registered before. The increase of its intensity simultaneously with other lines corresponding to the molecular hydrogen enables one to suppose that this line also can be associated with hydrogen molecules in silicon. 
The final step of our experiments was annealing of the samples at $350^{\circ} \mathrm{C}$ for $60 \mathrm{~min}$. This annealing accompanied by the surface modification led to disappearance of all hydrogen related lines in the Raman spectra.

\section{Summary}

In the Raman spectra taken under excitation of cone-shaped defects formed on the surface of helium implanted, annealed and hydrogen plasma treated $\mathrm{Cz} \mathrm{Si}$ wafers, we observed the lines corresponding to the molecular hydrogen localized in tetrahedral interstitials $\left(\approx 3621 \mathrm{~cm}^{-1}\right)$, multivacancies $\left(\approx 3820 \mathrm{~cm}^{-1}\right)$ and silicon defects $\left(\approx 4144 \mathrm{~cm}^{-1}\right)$. The simultaneous registration of these lines can testify the complex structure of the cone-shaped defects on the surface. Moreover, along with these known lines, we have observed also the lines at 3468 and $3698 \mathrm{~cm}^{-1}$, which were not observed before and are probably determined by molecular hydrogen, too.

\section{References}

[1] N.V. Frantskevich, A.V. Mazanik, A.V. Frantskevich, T. Kołtunowicz, P. Zukowski, Acta Phys. Pol. A 120, 105 (2011).
[2] K. Murakami, N. Fukata, S. Sasaki, K. Ishioka, M. Kitajima, S. Fujimura, J. Kikuchi, H. Haneda, Phys. Rev. Lett. 77, 3161 (1996).

[3] A.W.R. Leitch, J. Weber, V. Alex, Mater. Sci. Eng. B 58, 6 (1999).

[4] E.V. Lavrov, J. Weber, Phys. Rev. Lett. 89, 215501 (2002).

[5] T. Mori, K. Otsuka, N. Umehara, K. Ishioka, M. Kitajima, S. Hishita, K. Murakami, Physica B 302-303, 239 (2001).

[6] O. Moutanabbir, B. Terreault, M. Chicoine, F. Schiettekatte, P.J. Simpson, Phys. Rev. B 75, 075201 (2007).

[7] S. Socher, E.V. Lavrov, J. Weber, Phys. Rev. B 86, 125205 (2012).

[8] Y.L. Huang, Y. Ma, R. Job, W.R. Fahrner, Appl. Phys. Lett. 86, 131911 (2005).

[9] M. Hiller, E.V. Lavrov, J. Weber, Phys. Rev. B 80, 045306 (2009).

[10] W. Düngen, R. Job, Y. Ma, Y.L. Huang, T. Mueller, W.R. Fahrner, L.O. Keller, J.T. Horstmann, H. Fiedler, J. Appl. Phys. 100, 034911 (2006). 